\title{
A MANIPULAÇÃO INFORMATIVA E SEU MODUS OPERANDI NO ENQUADRAMENTO IDEOLÓGICO NAS REDES SOCIAIS
}

\author{
Eduardo Alves da Silva ${ }^{\mathrm{a}}$ \\ Paulo Henrique Duque
}

\begin{abstract}
RESUMO:
O presente estudo lança luz à questáo do processo manipulativo de informaçóes veiculadas nas redes sociais por meio do processo de framing e reframing. Com base em uma abordagem qualitativa, o artigo apresenta o modo como o fluxo de informaçóes veiculadas por fake news nas redes sociais se efetiva no sentido da construção, desconstrução e reconstrução de frames.
\end{abstract}

PALAVRAS-CHAVE: frames; framing; reframing.

Recebido em: 29/05/19

Aprovado em: 04/10/19

\section{Introdução}

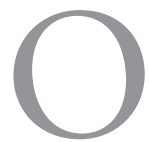

ato de comunicação está ligado a seus falantes e sua estrutura contextual, não podendo ser categorizado de forma discreta. Os falantes de uma língua estão inseridos em pacotes contextuais de ampla complexidade e sempre em movimento. A língua não é objeto estático e inerte. Sua

a Mestre em Linguística teórica e descritiva pela Universidade Federal do Rio Grande do Norte (UFRN), pesquisador do grupo Cognição e Práticas Discursivas do Departamento de Pós-Graduação em Estudos da Linguagem (PPgEL/UFRN)

b Doutor em Linguística (UFRJ/RJ). Professor do Departamento de Letras da Universidade Federal do Rio Grande do Norte (UFRN) e docente do quadro permanente do Programa de Pós-Graduação em Estudos da Linguagem (PPgEL). 
dinâmica muda conforme os seres humanos se modificam e seus contextos de aparecimento são igualmente dinâmicos.

Com o advento da revolução tecnológica da sociedade da informação, o homem passou a desenvolver uma relação mais democrática com o conhecimento e o uso que se faz dele. Como uma das suas consequências, temos o surgimento das redes sociais, que permitiram não só a ampliação desse alcance comunicativo mas também tem servido a muitos interesses que vão da simples referenciação até intençóes políticas e disseminação de fake news.

Qual o propósito da linguagem no mundo do hipertexto das redes sociais? Por que pessoas dentro de um mesmo nicho sociocultural possuem visões de mundos tão distintas dentro desses veículos de comunicação cibernética? Como a intenção comunicativa dos textos, em época de ferrenhos debates políticos na internet, parece ser objeto de controle e manipulação das pessoas?

Alguns grupos enxergam as redes sociais como meio disseminador do conhecimento, enquanto outros a consideram um meio de distorcer a funçáo do enunciador ou um meio para manipular massas. De toda sorte, qual é a função da linguagem dentro do ambiente virtual das redes sociais?

Neste artigo, avaliamos a montagem do aparato manipulativo do fluxo de informaçóes nas redes sociais como forma de induzir, guiar ou manipular as pessoas em direção a um enquadramento específico. Da mesma forma, propomos um modelo para sua análise. Para o entendimento desse recente fenômeno social, apoiamo-nos na perspectiva qualitativa de Silverman (2005) e relacionamos à área autores que se aplicam ao estudo de frames e framing (DUQUE, 2015a, 2015b, 2016, 2017; LAKOFF, 2004, 2008), sob uma perspectiva ecológica de cognição e linguagem (DUQUE, 2015b, 2017).

\section{Metalinguagem das redes sociais}

A metalinguagem é definida pelo uso da linguagem para explicar a própria linguagem. Dessa forma, o ato de comunicaçáo se configuraria, conforme Jakobson (1977) pensaria, por meio de uma mensagem qualquer que contivesse um conteúdo e um destinatário. Para tanto, seria preciso que a própria linguagem se reutilizasse dos próprios atributos para a obtenção de sentido. 
Jakobson ensina que o próprio ato de interpretar o mundo a nossa volta, usando os próprios signos para seu entendimento, constitui uma metalinguagem. Nas redes sociais, o que vemos é a explicação da linguagem pela própria linguagem veiculada por uma interface gráfica. A metalinguagem na construção de sentido é uma problemática que parece não só ter chamado a atenção do célebre linguista russo, mas também ser questão pontual em dias de comunicação virtual e fake news.

No ambiente virtual das redes sociais, o uso da metalinguagem está a serviço de um enquadramento de ideias dentro de muitos cenários, inclusive do político. Essa metalinguagem é, na verdade, um jogo de linguagem que toma os manipuladores das informaçóes como ponto de partida e o público que se pretende alcançar como ponto de chegada.

O jogo de linguagem, dentro da perspectiva ecológica, é uma negociação de sentido que "necessita de um grupo de indivíduos (pelo menos dois), um contexto e um propósito comunicativo, de modo que recursos pragmáticos façam parte do processo desde o início" (DUQUE, 2016, p. 164). Esse jogo de linguagem estrutura novos enquadramentos para ideias e conceitos e guia a compreensão de sentido daqueles que desejam a aceitação de seus próprios frames e ideias pelo grupo em contrapartida. Frames não apenas guiam a conceptualização, mas orientam a construção de novos frames, remodelam os já existentes e até desconstroem outros, destruindo a estruturação conceptual prévia.

Nesse contexto, temos as redes sociais que definem a maneira como as pessoas expressam suas opinióes e exteriorizam seus atos de fala. A internet é um meio metalinguístico de produção de linguagem. É a partir (e por meio) dela que vemos que os vários usos da linguagem parecem destoar do ato verbal e presencial de uma conversaçáo comum.

\section{Framing e reframing: além da reconstrução de ideas}

Frames são esquemas cognitivos não imagéticos que envolvem um conjunto de conceitos inter-relacionados (constituência) e que orientam uma estratégia de percepção (indireta) e de interpretação utilizada pelas pessoas a fim de compreender e de dar respostas ao mundo. Dessa forma, o frame é, antes de mais nada, uma forma de categorizar e conceptualizar as coisas. 
O processo de manipulação e orientação de sentido passa inevitavelmente pela construção desses frames, que são modelos conceptuais que desenvolvemos para dar sentido ao nosso entorno. Temos ideias e conceitos sobre as coisas que não são necessariamente iguais às do nosso interlocutor no jogo de linguagem. No caso específico das redes sociais, um grupo conhece muito bem o jogo de linguagem que precisa utilizar para fazer com que seus frames sejam os mesmos por ele propostos. Essa negociação de sentido é amplamente ecológica, pois leva em consideração, além do jogo de linguagem, nosso entorno sociocultural para a construção de sentido. Passamos a perceber nossos conceitos de forma diferente para nos convencer das ideias do outro. Esse processo não teria sentido caso não se utilizassem as noçóes de framing e reframing. O framing é um instrumento conceptual para construirmos sentido para a vida, tanto de maneira verbal como semiótica. Podemos relacionar diversas formas de como a construção do frame pode ocorrer. A tessitura das ideias valorativas de um enquadramento pode ser feita por complementação, desconstrução ou até agregação de valores já existentes. Aqui, definimos as possibilidades construtivas para o processo de reframing. $\mathrm{O}$ reframing é a atualização de frames ou o remodelamento dos valores do frame. No processo de reframing, todo o frame é remodelado a partir de suas bases antigas com vistas a se transformar num frame totalmente novo. $\mathrm{O}$ reframing é subdividido em deframing, coframing e hiperframing (figura 1).

Figura 1 - Processo de framing e reframing.

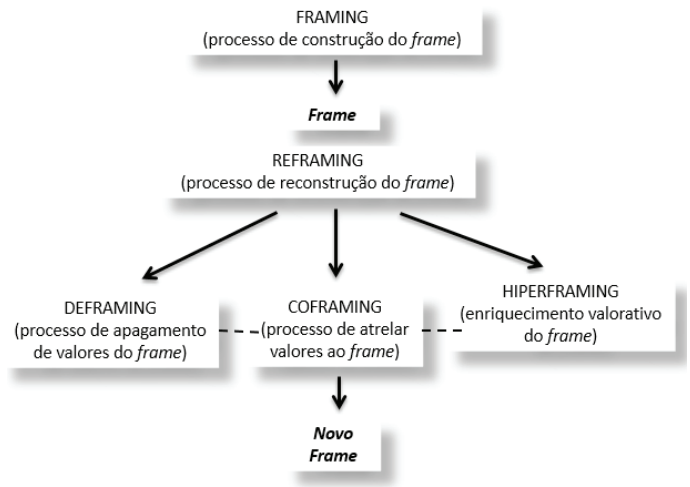

Fonte: Elaborada pelos autores. 
O deframing ${ }^{1}$ é uma operação de framing que visa à desconstrução de um frame prévio. Quando ocorre um deframing, os valores associados ao frame perdem força ou até desaparecem. Uma característica antes expressiva passa a ganhar menos valor ou até deixa de ser relevante. Tomemos como exemplo o frame UNIVERSIDADE (figura 2).

\section{Figura 2 - Frame UNIVERSIDADE.}

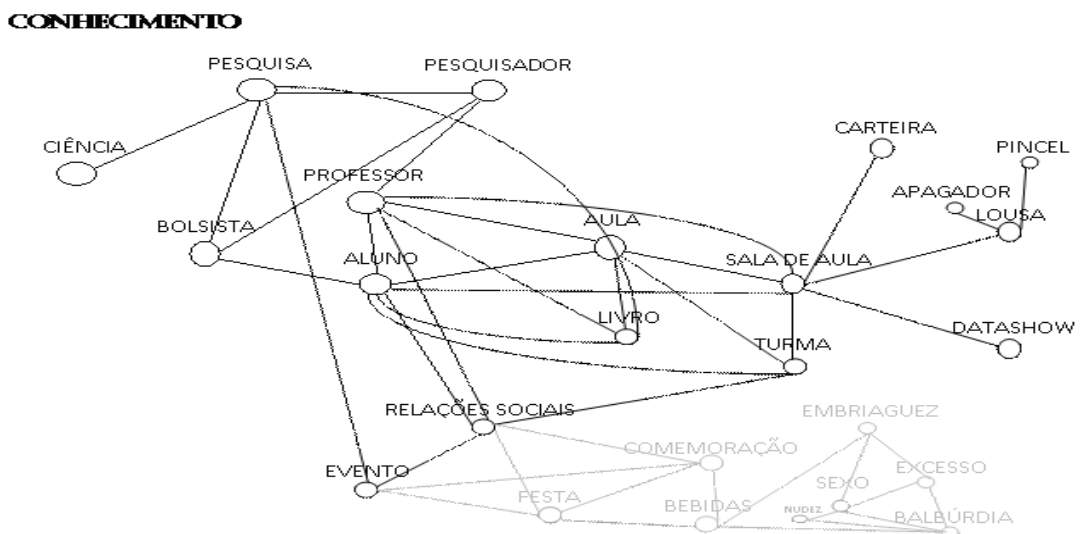

Fonte: Elaborada pelos autores.

Devido às múltiplas estratégias ecológicas (multimodais) efetivadas num determinado jogo de linguagem, o frame passa a perder conceitos relevantes à universidade. $\mathrm{O}$ uso de informaçóes imprecisas, e até mesmo falsas, dentro do contexto da rede social (normalmente de hipertextos multimodais), com imagens e frases curtas para formação do frame, vai levando o compreendedor dessa mensagem a repensar a forma como vê o conceito UNIVERSIDADE. Essa manipulação pode dar-se com manchetes de fake news, frases atribuídas a outras pessoas, episódios descontextualizados, fotografia, áudios ou uso de símbolos que remetem a outros frames. Se a intenção do participante do jogo de linguagem é, por exemplo, fazer com que as pessoas vejam a universidade

1 A visão ecológica adotada neste artigo não se confunde com a abordagem de Wendland (2010) na utilização dos conceitos de co-framing, de-framing e hyper-framing. 
como lugar subversivo e de práticas incompatíveis com o ambiente acadêmico, ele desgasta esse aspecto do frame UNIVERSIDADE até que ele desapareça, conforme a figura 3.

Figura 3 - Frame UNIVERSIDADE sob deframing.

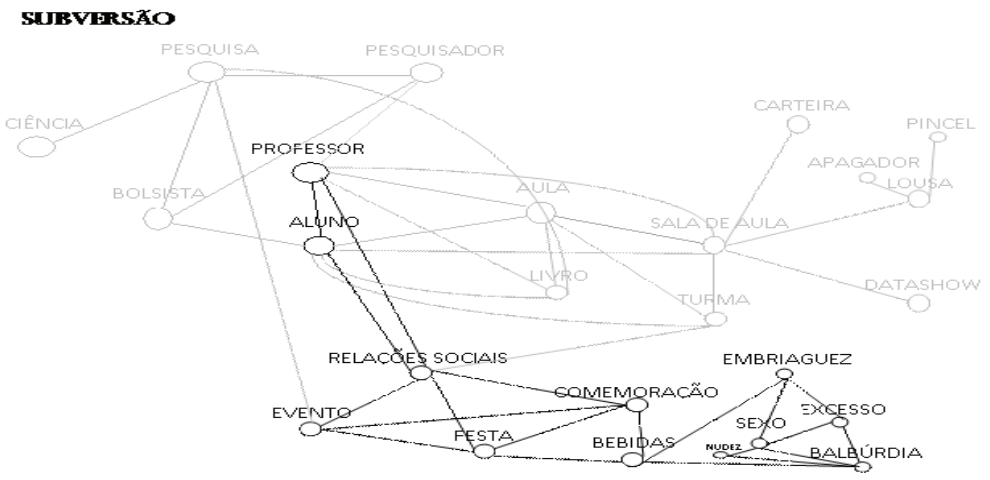

Fonte: Elaborada pelos autores.

Posteriormente, esses frames podem ou não ganhar outros conceitos associados a esse enquadramento. Caso isso ocorra, o que temos é o coframing, que é o modo como o reframing complementa com informaçóes um frame específico ou um grupo deles. O frame passa a agregar valores que não continha antes da realização do jogo de linguagem. Novas informaçôes são consolidadas nesse enquadramento, que vai ganhando importância conforme a estratégia manipulativa do jogo de linguagem ocorre. No caso do nosso exemplo, imaginemos que a intenção manipulativa do operador do jogo de linguagem seja incutir na mente de seu público a ideia de que a universidade não seja um espaço ordeiro, mas lugar de balbúrdia e subversão. O âmbito acadêmico seria, segundo suas intenções de enquadramento, lugar de subversão, não de produção de conhecimento, conforme ilustrado na figura 3. Dessa forma, dentro do jogo de linguagem, a noção de que UNIVERSIDADE É CONHECIMENTO iria sendo recomposta gradativamente até que a vontade do manipulador objetivasse sua intenção: desconstruir valores associados a uma ideia e substituí-los por outros, a noção de que UNIVERSIDADE É SUBVERSÃO. 
O movimento oposto também é possível. Nem sempre se diminuem os valores de um frame. Muitas vezes, é preciso agregar a ele mais conceitos relacionados. A isso damos o nome de hiperframing. No hiperframing, ocorre uma supervaloração informativa do frame modelado num determinado jogo de linguagem: detalhamento da estrutura conceptual dos leitores/ouvintes por meio de inserção ideológica e valorativa de novos conceitos (figura 4).

Figura 4 - Frame UNIVERSIDADE sob coframing.

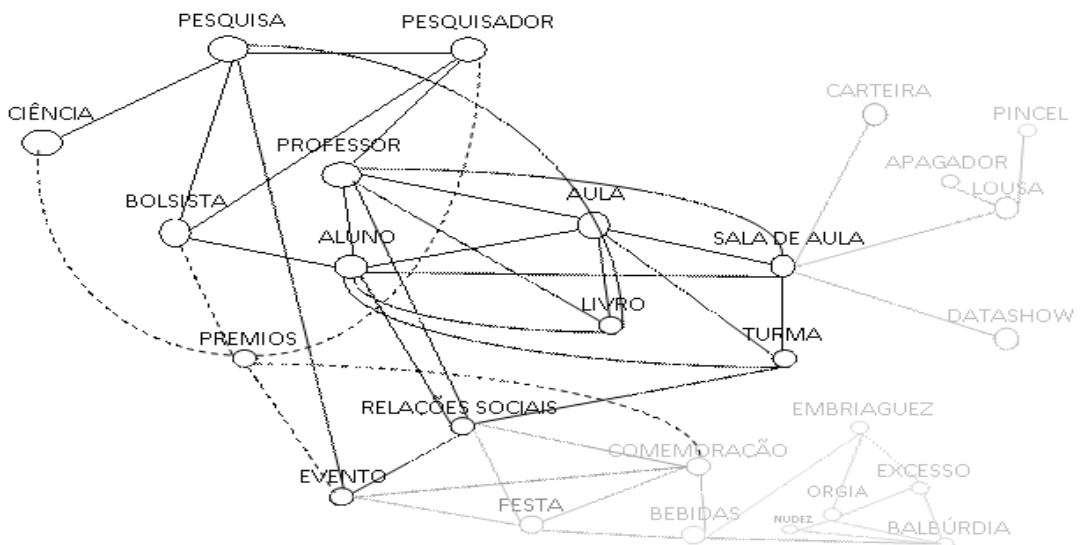

Fonte: Elaborada pelos autores.

O hiperframing recorre ao uso de aspectos multimodais para sua efetivação como forma de auxiliar o processo de enquadramento. Nas redes sociais, vemos toda sorte de informaçóes audiovisuais que o hipertexto proporciona, o que leva a prática do hiperframing a ser facilitada.

O reframing, conforme propomos explicar neste artigo, lança mão de ferramentas de compreensão de como o jogo de linguagem ocorre dentro das redes sociais no sentido de levar a uma manipulação informativa. Essa orientação em direção ao novo significado dos frames é amplamente ecológica, pois leva em conta náo apenas nosso contexto informacional sobre determinada coisa, mas também nosso entorno físico, ambiental, emotivo e situacional para efetivação. Nossa relação di- 
reta com esses pontos e com a forma de existência de sua contrapartida, sempre ocorrendo no aqui e no agora, estrutura o entendimento dentro do jogo de linguagem das redes socais. No entanto, de que modo ocorre o processo manipulativo dessas operaçóes de reframing?

Na próxima seção, vamos colocar em prática o modelo aqui proposto de reestruturação de sentido dentro de nossa perspectiva ecológica de framing e indicar de que forma tal reestruturação ocorre nas redes sociais em tempos de fake news.

\section{O processo de manipulação de informações}

O ambiente virtual das redes sociais vem ganhando cada vez mais espaço na nossa prática comunicativa. Os jogos de linguagem também devem adequar-se a essas demandas. O participante do jogo de linguagem vai apropriar-se das informações ecológicas disponíveis para que sua intenção, no ato do framing, faça sentido e obtenha o resultado desejado.

Nas redes sociais, levamos o outro a formar conceitos sobre um assunto qualquer e utilizamos todo aparato multimodal disponível para o jogo de linguagem. Para tanto, fornecemos não apenas itens lexicais para a leitura mas também nossos próprios julgamentos de valores, intencionalidade, cenários mentais e, até mesmo, cargas emocionais e estados de espírito. No momento em que executamos um jogo de linguagem, estamos interessados na concretização de nossas intenções para que o outro seja receptivo. Sobre isso, Brown e Levinson (1987) defendem que estamos preocupados com a manutenção da face valorativa do outro na construção de sentido. Sem a conservação dessa face valorativa, nossa intenção de convencimento se destruiria.

Quando operamos o framing e reframing, estamos direcionando o foco de atenção do participante do jogo de linguagem para determinados aspectos em detrimento de outros. Nas redes sociais, no caso específico da manipulação de informaçóes, quem propóe o reframing precisa lançar mão das operaçóes de enquadramento e desenquadramento. Tomemos como exemplo o caso da figura 5 para ilustrar o que foi dito neste parágrafo. 
Figura 5 - Pintura sob efeito de reframing.

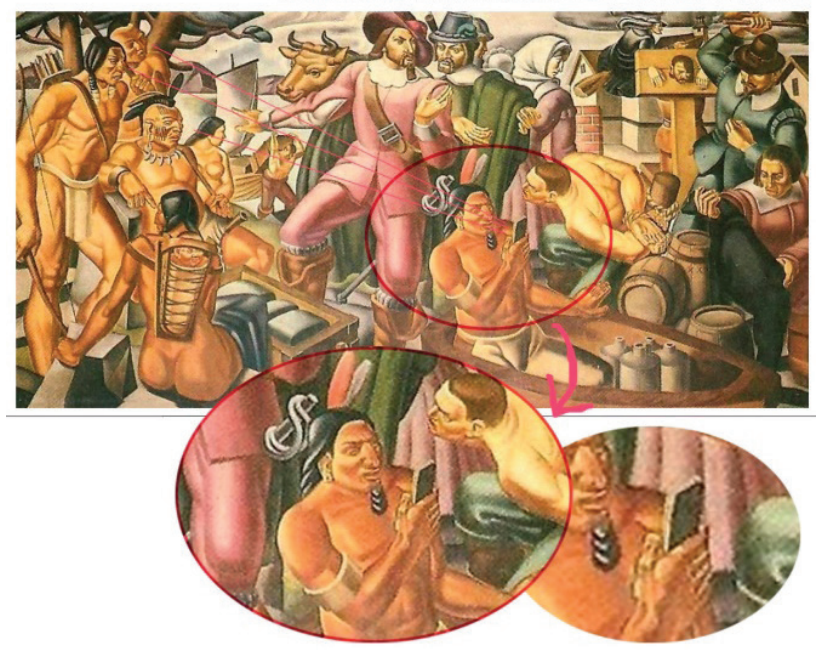

Fonte: https://marcosmauricio.blogspot.com/2017/09/misterio-pintura-mostra-desenho-de.html.

Na figura 5, o recorte da pintura "Mister Pynchon e o assentamento de Springfield", de Umberto Romano, ilustra uma das fake news que começou a se difundir na rede mundial de computadores. Essa fake news lançou o questionamento de como uma pintura de 1937 teria mostrado um índio primitivo portando um smartphone. O que ocorre aqui é uma série de operaçóes de framing e reframing. Se imaginássemos uma pessoa num shopping center segurando um smartphone, isso náo nos causaria estranheza. No entanto, dentro do contexto da obra, seria improvável que o índio estivesse carregando consigo um telefone celular. Nas redes sociais, o exemplo foi apresentado com um título tendencioso e com um tom de mistério. Levaria à luz um debate de como um artista retratou um iphone numa época em que não havia essa tecnologia, sugerindo uma viagem no tempo.

A intenção de quem veiculou essa fake news, dentro do seu jogo de linguagem, parece ter sido convencer seu público de que a viagem no tempo realmente existe. No caso, o que temos, sem a indução manipulativa por reframing, é que o índio, na verdade, segurava um pequeno espelho. No entanto, a intenção do manipulador foi possivelmente desconstruir o frame e incutir seus 
valores no processo de reframing. Ele influenciou a construção de sentido no intuito de forjar suas próprias intençóes com quem participa do jogo de linguagem. Por meio do ocorrido e de sua apresentação para um público muito mais versado em hipertexto e contextos sobre smartphones, o manipulador dá indícios de que forjou uma desconstrução por deframing da estrutura original do enquadramento, levando o alvo a realizar um reframing inserindo um valor diferente do originalmente pensado.

$\mathrm{O}$ mesmo ocorre quando, nas redes sociais, circulam imagens com montagens de celebridades declarando apoio a determinado candidato ou partido político. Normalmente, uma celebridade (artística ou intelectual) está vinculada a uma série de ideias, valores e frames próprios que recuperam toda sua entidade. Para uma celebridade que tem seu enquadramento relacionado ao bem-estar social, altruísmo, pacifismo e tolerância, seria incoerente vê-la representando ideais fascistas, por exemplo. No caso específico de, digamos, um pacifista como Mahatma Gandhi aparecer numa fake news usando uma camiseta de amor à guerra, isso desconstruiria totalmente seu enquadramento pacifista por deframing. Como essa é uma figura que já não vive mais e nunca houve registro de algo assim pela retidáo de sua postura, seria difícil reenquadrar e desconstruir o frame de paz a ele associado. Isso dificultaria o processo manipulativo por parte daquele que propôs o jogo de linguagem no sentido de fazer ganhar valoração o fato de Gandhi ser, na verdade, um fascista.

No entanto, para um ganho qualitativo, o manipulador utiliza-se de exemplos mais tangíveis para a concretude de seu jogo de linguagem. Para que as operaçóes manipulativas de reframing ganhem subsídios para sua efetivação, o operador do jogo de linguagem faz com que suas ideias entrem na mente dos seus alvos. Lakoff (2004) afirma que "reframing nấo é apenas sobre palavras e linguagem. Reframing diz respeito a ideias. As ideias têm que estar no lugar no cérebro das pessoas antes que o som possa fazer algum sentido" (LAKOFF, 2004, p. 105, traduçáo nossa ${ }^{2}$ ). Dessa forma, o reframing incute ideias nas mentes das pessoas, ideias estas que levam ao processo de ressignificação. $\mathrm{O}$

2 Refaming is not just about words and language. Refaming is about ideas. The ideas have to be in place in people's brains before the sound bite can make any sense. 
intuito do manipulador, no jogo de linguagem político das redes sociais, é o de incitar uma mudança de postura ideológica. O reframing, antes de mais nada, almeja a mudança social (LAKOFF, 2004).

A ideia a ser desconstruída pelo manipulador deve fazer sentido não apenas na realidade dele, mas, especialmente, na realidade de seu público. Quando uma fake news atinge uma parcela da população digital de uma rede social, ela procura desconstruir uma realidade previamente construída para adequá-la às intençóes do manipulador. A intenção do propagador da fake news é a busca pela verdade. Essa verdade é a verdade do manipulador, adequada às suas expectativas. Lakoff (2008) afirma que "nós pensamos usando frames conceituais. Palavras nomeiam elementos desses frames. Sem frames e nomes, é difícil pensar e falar sobre verdades”. (LAKOFF, 2008, p.133, tradução nossa ${ }^{3}$ ). $\mathrm{O}$ autor afirma, ainda, que as memórias não são armazenadas de forma sólida, pois elas estão sempre em mudança situacional. Estão sempre passíveis de mudança para se adequarem à nova verdade (LAKOFF, 2008).

A estratégia de desconstrução e reconstrução de enquadramentos por parte do manipulador ocorre em mão dupla tanto em sua afirmação, quando em sua negação. No entanto, se possuirmos um enquadramento em estado de hiperframing, totalmente sólido em relação à estratégia proposta no jogo de linguagem do manipulador, não deixamos nosso enquadramento de um frame ser mudado. O reframing é mais fácil de ocorrer entre pessoas que estão mais envolvidas nas intençôes do manipulador. No caso específico das redes sociais, o reframing, em sua condição de negação, também influenciaria uma parcela de internautas que não receberam instrução sobre (ou não sabem) como verificar as fontes dos dados antes de assumir a ideia proposta no jogo de linguagem. Numa proposição de reframing malsucedida, o que falta como componente do jogo de linguagem veiculado pelas fake news não são itens lexicais ou falta de oratória. Lakoff (2004) expressa que a falha na formação de frames não é pela falta de palavras, mas de ideias. Se não há uma nova ideia a ser incorporada ao frame do alvo, não há framing.

3 We think using conceptual frames. Words name elements of those frames. Without frames and names, it is difficult to think and talk about truths. 
Bybee (2011) esclarece que os tokens da experiência linguística são categorizados e combinados com tokens similares de experiência que foram previamente armazenados como exemplares. Nesse sentido, se o reframing não ocorrer imediatamente na primeira tentativa, o manipulador continuará insistindo com mais e mais frequência. A cada token de repetição linguística ou valorativa, o alvo irá, pouco a pouco, sofrendo o reenquadramento de seu ponto de vista até que seu frame esteja totalmente adequado aos interesses do manipulador.

As palavras em si não contêm significado. A flexibilização semântica só pode ser dada pelo reframing. As palavras (que veiculam frames inteiros) possuem força simbólica. Se uma pessoa se afeta por seu significado dentro de um jogo de linguagem é porque a simbologia dessa palavra não tinha frequência o suficiente. Se não é afetada é porque o indivíduo já possui uma carga simbólica muito grande para ser desconstruída por uma única fake news dentro da rede social. Sobre a força simbólica das palavras, Bybee (2011) defende que os itens lexicais apresentam graus de força diferentes em razão, principalmente, da sua frequência simbólica.

O jogo de manipulaçáo é complexo e amplamente conhecido pelo disseminador de fake news. Nas redes sociais, é intenção do manipulador fazer com que as ideias que tenta disseminar entrem e se incutam nos frames de seus alvos. Em muitos casos, logrará êxito e, em outros, terá mais trabalho, precisando usar esse artifício com maior frequência. $O$ processo de manipulação é, antes de mais nada, uma estratégia ecológica pois, com efeito, leva em consideração o nicho sociocultural do alvo.

\section{Conclusão}

As operaçôes de framing e reframing são a base para a compreensão do processo manipulativo de ideias veiculadas nas fake news. Sua intenção vai além de disseminar a notícia falsa, involuntariamente ou por mero desconhecimento. Antes de mais nada, estamos tratando de um complexo jogo de linguagem, que pretende desconstruir ideias para reformulá-las em prol do interesse do enunciador.

Neste artigo, apresentamos as peças participantes do processo de reframing. A primeira delas é o deframing, responsável pelo apagamento de valores 
e ideias associados a um frame. Em seguida temos o coframing, que intenta uma alocação e agregação de valores alheios a um frame dado na tentativa de servir aos interesses do manipulador no jogo de linguagem. Finalmente, propomos o hiperframing, que é a supervaloração de um frame.

Os conhecedores dos frames lançam ideias rasas, que são compradas pelos alvos e têm enquadramentos acessíveis, preparando o público para o reframing . Essas ideias são gradativamente incutidas nos frames dos participantes por meio de um jogo de linguagem que, pouco a pouco, vai garantindo o reenquadramento do novo conceito.

O uso estratégico de manipulação de informaçóes é possível em qualquer contexto. No entanto, evidenciamos aqui que esse fato é mais frequente no ambiente das redes sociais por sua atual popularidade, seu alcance quantitativo e sua essência multimodal, o que permite uma certa facilidade para o manipulador. A eficácia das operaçóes de reframing pode transformar uma ideia simples em algo extraordinário, altamente aceito e facilmente disseminado como ideia. Do mesmo modo, um frame rico no tocante ao seu conteúdo valorativo pode transformar-se num abjeto desprezível com esse tipo de estratégia manipulativa.

\section{Referências}

BROWN, Penelope; LEVINSON Stephen. Politeness: Some Universals in Language Usage. Cambridge: Univ. Press, 1987. p. 345.

BYBEE, Joan Lea. Language, Usage and Cognition. Cambridge: Cambridge Univ. Press, 2011. p. 264.

DUQUE, Paulo Henrique. Discurso e cognição: uma abordagem baseada em frames. Revista da ANPOLL, 1, 39: 25-48. Florianópolis, 2015a.

. A emergência do comportamento linguístico. Revista Virtual de Estudos da Linguagem, 14, 27: 151-172, Porto Alegre, 2016. . De perceptos a frames: cognição ecológica e linguagem. SCRIPTA, 21, 41: 21-45, Belo Horizonte, 2017.

. Por uma abordagem ecológica da linguagem. Pontos de Interrogação:

Revista de Critica Cultural, 5, 1: 55-78, Alagoinhas, 2015b. 
JAKOBSON, Roman. Linguística e Comunicação. São Paulo: Editora Cultrix, 1977. p. 168LAKOFF, George. Don't Think of an Elephant: Know Your Values and Frame the Debate: 1. ed. White River Junction: Chelsea Green Pub. Co., 2004. p. 168 _. The Political Mind: Why You Can't Understand 21st-Century American Politics with an 18th-Century Brain. New York: Viking, 2008. p.316.

SILVERMAN, David. Doing qualitative research: a practical handbook. London: Sage Publications, 2005. p.416.

WENDLAND, Ernst Richard. Framing the Frames: A Theoretical Framework for the Cognitive Notion of "Frames of Reference." Journal of Translation, 6, 1: 27-50. Texas, 2010.

\title{
THE INFORMATIVE MANIPULATION AND ITS MODUS OPERANDI IN THE IDEOLOGICAL FRAMEWORK IN SOCIAL NETWORKS.
}

\begin{abstract}
:
The present paper sheds light on the issue of the manipulative process of information disseminated in social networks through the process of framing and reframing. Based on a qualitative approach, the article presents the way in which the flow of information transmitted by fake news in social networks is effective in the direction of the construction, deconstruction and reconstruction of frames.
\end{abstract}

KEYWORDS: frames; framing; reframing. 